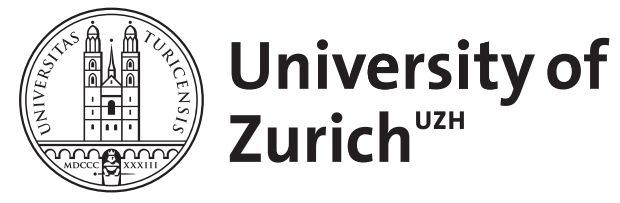

\title{
Developments in cancer immunotherapy
}

\author{
van den Broek, M ; von Boehmer, L ; Knuth, A
}

\begin{abstract}
Significant advances have been made in the field of cancer immunology and immunotherapy over the last three decades. An important step forward was the identification of human cancer antigens eliciting spontaneous immune responses in cancer patients. The most immunogenic human cancer antigens known to date belong to the cancer-testis family of antigens, which are proteins expressed in various types of cancer but not in any healthy tissues except germ cells. The aim of cancer immunotherapy is to induce or boost the existing tumor-specific immune response by vaccinating with a relevant antigen together with an adjuvant. Immunization together with an adjuvant will induce a strong and effective immune response or can qualitatively and quantitatively improve existing responses. As selective outgrowth of antigen-loss variants due to immunoediting in vivo may occur during vaccination of cancer patients, singular metastatic failure sites of disease should be surgically removed and tested for antigen expression as antigen-negative (or loss) variants may have survived the pressure of the immune system. At this rather early stage of development, cancer immunotherapy should be offered to cancer patients only within carefully monitored clinical trials of experienced clinical research teams. In addition, it may be rewarding to include patients with early-stage disease in immunotherapy trials, as immunoediting of the tumor and immune escape may be less pronounced. Copyright 2010 S. Karger AG, Basel.
\end{abstract}

DOI: https://doi.org/10.1159/000282064

Posted at the Zurich Open Repository and Archive, University of Zurich

ZORA URL: https://doi.org/10.5167/uzh-34661

Journal Article

Published Version

Originally published at:

van den Broek, M; von Boehmer, L; Knuth, A (2010). Developments in cancer immunotherapy. Digestive Diseases, 28(1):51-56.

DOI: https://doi.org/10.1159/000282064 


\title{
Developments in Cancer Immunotherapy
}

\author{
Maries van den Broek Lotta von Boehmer Alexander Knuth \\ Department of Oncology, University Hospital Zurich, Zurich, Switzerland
}

\section{Key Words}

Cancer $\cdot$ Immunotherapy $\cdot$ Cancer-testis antigens clude patients with early-stage disease in immunotherapy trials, as immunoediting of the tumor and immune escape may be less pronounced.

Copyright $\odot 2010$ S. Karger AG, Basel

\begin{abstract}
Significant advances have been made in the field of cancer immunology and immunotherapy over the last three decades. An important step forward was the identification of human cancer antigens eliciting spontaneous immune responses in cancer patients. The most immunogenic human cancer antigens known to date belong to the cancer-testis family of antigens, which are proteins expressed in various types of cancer but not in any healthy tissues except germ cells. The aim of cancer immunotherapy is to induce or boost the existing tumor-specific immune response by vaccinating with a relevant antigen together with an adjuvant. Immunization together with an adjuvant will induce a strong and effective immune response or can qualitatively and quantitatively improve existing responses. As selective outgrowth of antigen-loss variants due to immunoediting in vivo may occur during vaccination of cancer patients, singular metastatic failure sites of disease should be surgically removed and tested for antigen expression as antigen-negative (or loss) variants may have survived the pressure of the immune system. At this rather early stage of development, cancer immunotherapy should be offered to cancer patients only within carefully monitored clinical trials of experienced clinical research teams. In addition, it may be rewarding to in-
\end{abstract}

\section{Immunological Control of Cancer}

Burnet, Thomas and Medawar put forward the concept of cancer immunosurveillance in the late 1950s. They postulated that the immune system recognizes transformed self, i.e. tumor cells that had undergone genetic aberrations significant enough to result in recognition by immune cells [1]. Several lines of evidence derived from murine tumor models, as well as from clinical data, support this concept. Today, cancer immunosurveillance or cancer immunoediting is thought to follow three phases: an early elimination phase, followed by an equilibrium phase where the immune system selects variants that may survive immune attacks, and an immune escape phase of cancer cell variants that may have altered their geno- or antigenic phenotype or may have come under the control of immunoregulatory phenomena. These three phases can occur simultaneously at different tumor sites, and not all three phases must occur during the interaction between tumor cells and the immune system [2-4].

Recent evidence obtained with methylcholanthreneinduced sarcomas in mice shows that the elimination and

\section{KARGER}

Fax +4161306 1234

E-Mail karger@karger.ch

www.karger.com
(C) 2010 S. Karger AG, Basel

$0257-2753 / 10 / 0281-0051 \$ 26.00 / 0$

Accessible online at:

www.karger.com/ddi
Alexander Knuth

Department of Oncology, University Hospital Zurich

Raemistrasse 100

CH-8091 Zurich (Switzerland)

Tel. +41 44255 9779, Fax +41 44255 4548, E-Mail alexander.knuth@usz.ch 
equilibrium phases are accomplished via the adaptive immune compartment: Depletion of $\mathrm{T}$ cells from or blockade of IFN (interferon)- $\gamma$ in apparently tumor-free immunocompetent mice resulted in rapid outgrowth of clinically occult tumors, which shows that $\mathrm{T}$ cells and IFN- $\gamma$ are instrumental in keeping occult tumors under control [5]. Additionally, in cancer patients there is ample evidence for immunological control of tumors. First, tumor-specific immunity can be detected in a proportion of cancer patients [6]. Second, the risk of developing a tumor greatly increases in immunocompromised patients, such as AIDS patients or organ transplant recipients. Third, correlative studies indicate that the presence of tumor-infiltrating lymphocytes may be associated with improved clinical outcome in several cancers including melanoma, colorectal, breast, prostate, renal cell, esophageal and ovarian carcinomas [7-13]. In particular, recent data in epithelial ovarian cancer indicated significant differences in the distributions of progression-free survival and overall survival according to the presence or absence of intratumoral $\mathrm{T}$ cells. The five-year overall survival rate was $38.0 \%$ among patients whose tumors contained $\mathrm{T}$ cells and $4.5 \%$ among patients whose tumors did not. In addition, ovarian cancer patients, whose tumors are infiltrated by $\mathrm{CD} 4+\mathrm{CD} 25+\mathrm{FoxP} 3+$ regulatory $\mathrm{T}$ cells $\left(\mathrm{T}_{\text {reg }}\right)$, demonstrated reduced survival [14]. Fourth, after transplanting kidneys from a patient who died of a stroke and was supposedly cured of an early stage melanoma 16 years back to two independent recipients, both recipients developed donor-derived metastatic melanoma under immunosuppressive treatment [15].

Tumors escape destruction by the immune system via a variety of active, regulatory mechanisms. These include downregulation of major histocompatibility complex (MHC) molecules and/or the immunologically targeted antigens by the tumor cells, stimulation of inhibitory receptors such as cytotoxic $\mathrm{T}$ lymphocyte antigen-4 (CTLA-4) or PD-1 on T cells, induction of increased tumor infiltration by regulatory $\mathrm{CD} 4+\mathrm{CD} 25+\mathrm{FoxP} 3+\mathrm{T}$ cells $\left(\mathrm{T}_{\text {reg }}\right)$, or the production of immunosuppressive mediators such as IL-10, TGF- $\beta$, indoleamine 2,3 -dioxygenase by the tumor cells, stroma or infiltrate [2]. The often patchy expression of MHC molecules and tumor-associated antigens in tumor biopsies is indicative of the dynamic process of tumor escape, and it was observed in some clinical vaccination studies that the new metastases, which developed after initial clinical response, lost expression of MHC class I or of the targeted antigen.

CTLA- 4 is one of the crucial negative regulators of the adaptive immune response and it is known now that
CTLA- 4 has a central role in the induction and maintenance of peripheral $\mathrm{T}$ cell tolerance. This is illustrated by the fact that mice lacking CTLA-4 die of generalized autoimmunity and inflammation at the age of 3 weeks [16]. It is thought that peripheral $\mathrm{T}$ cell tolerance occurs in cancer patients as a result of chronic and suboptimal antigen stimulation and of the self-nature of many tumorassociated antigens and that this limits $\mathrm{T}$ cell-mediated anti-tumor effector responses. For this reason, the therapeutic effect of CTLA- 4 blocking antibodies was tested in mouse models and cancer patients, and showed encouraging results. Currently, clinical studies are being performed in which anti-CTLA-4 treatment is combined with simultaneous immunization, which is expected to have a higher efficacy than CTLA- 4 blockade alone. PD-1 is another molecule that is expressed on T cells and is involved in induction and maintenance of peripheral $\mathrm{T}$ cell tolerance. There is evidence that the ligands for PD-1, PD-L1 and PD-L2 are expressed by a proportion of tumor cells, and the first clinical studies in which cancer patients receive treatment with monoclonal antibodies that block PD-1 are being performed at present.

$\mathrm{CD} 4+\mathrm{CD} 25+\mathrm{FoxP} 3+\mathrm{T}_{\text {reg }}$ are crucial in preventing immune responses to self-antigens. They do this by interfering with the maturation of dendritic cells and by directly suppressing effector $\mathrm{T}$ cells $\left(\mathrm{T}_{\text {eff }}\right)$ through cell-cell interactions and/or soluble factors, including CTLA-4, IL-10 and TGF- $\beta$. The percentage of $\mathrm{T}_{\text {reg }}$ in the peripheral blood of healthy individuals and cancer patients is similar and is $2-5 \%$ of CD $4+$ cells. In tumors, however, this percentage is often dramatically increased, such that the ratio of $\mathrm{T}_{\text {eff }}$ to $\mathrm{T}_{\text {reg }}$ is low. Retrospective analysis in patients with ovarian carcinoma showed a correlation between the $T_{\text {eff }}$ to $T_{\text {reg }}$ ratio and survival time, with a low ratio being a poor prognostic factor [17]. Patients with prostate cancer who were treated with anti-CTLA- 4 and had a clinical response showed an increase in the $T_{\text {eff }}$ to $\mathrm{T}_{\text {reg }}$ ratio in some cases. In addition, $\mathrm{T}_{\text {reg }}$ depletion in different mouse models for cancer resulted in better tumorspecific $\mathrm{T}$ cell responses and a better control of tumors [18].

\section{Antigen Discovery and Classes of Tumor-Associated Antigens}

The era of modern cancer immunology started with observations made in two patients (SK-29 and MZ-2) with recurrent metastatic melanoma, who have been observed since 1978 and 1982, respectively. Both patients 
received intradermal immunizations with irradiated autologous tumor cells for an extended period of time and complete regression of tumor manifestations in the presence of $\mathrm{T}$ cell responses and strong increasing $\mathrm{T}$ cell responses under vaccination was documented. The patients, still alive, have remained free of disease ever since (for more than 2 decades now). Based on this favorable clinical effect, a systematic search was initiated to identify and characterize the cancer antigens and immune effector mechanisms that mediate tumor regression and tumor control in vivo. A few years later, the first reports on spontaneous tumor-specific $\mathrm{T}$ cell responses were published [19]. Thierry Boon and colleagues cloned the first $\mathrm{T}$ cell-defined human cancer antigens from these patients in 1991: MAGE-1, tyrosinase and Melan-A. Since the initial reports by Boon and colleagues [20], a large number of tumor-associated antigens have been identified using similar approaches, e.g. BAGE, GAGE, and many others.

Some antigens were identified by serological analysis of recombinant cDNA expression libraries (SEREX): here, an expression library is incubated with patient serum, the cDNA clones that are recognized by the serum IgG are isolated, and the recognized protein is cloned and identified [21]. Examples of tumor-associated antigens that were identified by SEREX are SSX, NY-ESO-1, CT7, Rab38, NY-CO-58 and NY-BR-1.

Besides SEREX- and T cell-defined antigens, some antigens were discovered by cancer-induced antibodies. Typically, these antigens are (over)expressed on the surface of cancer cells and include gp75/TRP-1, p96 and Her2/neu.

Nowadays, tumor-associated antigens are classified into one of the following categories: (1) cancer-testis (CT) antigens, restricted expression in germ cells and cancer cells, e.g. MAGE, NY-ESO-1 and LAGE-1; (2) differentiation antigens, restricted to defined lineages like melanocytes, e.g. tyrosinase, Melan-A/MART-1 and gp 100; (3) mutated antigens, altered forms of constitutive proteins, e.g. CDK4, $\beta$-catenin, caspase- 8 and p53; (4) amplification antigens, e.g. overexpressed Her $2 /$ neu and $\mathrm{p} 53$; (5) splice variant antigens, e.g. NY-CO-37/PDZ-45 and ING1; (6) glycolipid antigens; (7) viral antigens, e.g. HPV, EBV.

Among all tumor antigens identified to date, the CT antigens are a distinct and unique class of differentiation antigens. The genes encoding CT antigens are frequently located on the $\mathrm{X}$ chromosome and are often members of multi-gene families. Furthermore, $10 \%$ of all genes on the $\mathrm{X}$ chromosome are CT antigens [22]. CT antigens are not expressed in healthy tissues, except germ cells, but are expressed by a proportion of different tumor types in a lineage-nonspecific fashion. Often, a particular tumor expresses more than one CT antigen. The frequency of CT antigen expression in many cancer types ranges from $5-40 \%$, with exceptionally high expression of individual CT antigens in certain cancers, e.g. high expression of MAGE-C1/CT7 in myeloma and NY-ESO-1 in $80 \%$ of synovial sarcoma [23, 24]. The function of CT antigens in germ cells and malignant cells is largely unknown. How their expression is regulated is also not known at present, but recent evidence suggests that epigenetic events, including DNA methylation and histone deacetylation, play a role. Some well-characterized members of the CT antigen family include MAGE, GAGE/PAGE/XAGE, NY-ESO-1/LAGE-1, SSX, SPANX, TRAG-3, BAGE, SCP1 , OY-TES-1 and CT10 [22, 25].

\section{Integrated Immune Responses in Cancer Patients: The NY-ESO-1 Paradigm}

NY-ESO-1 was initially identified by SEREX in New York from a patient with esophageal cancer, hence its name. NY-ESO-1 is a protein of 180 amino acids with a molecular weight of approximately $18 \mathrm{kDa}$, and its coding gene is located on the X chromosome (Xq28) [21]. The expression of NY-ESO-1 in healthy tissue is restricted to testicular germ cells, fetal ovary germ cells and trophoblastic epithelia of placental villi, all of which are MHC class I-negative. NY-ESO-1 is expressed at a variable frequency in several tumor types (fig. 1) and is considered to be the most immunogenic $\mathrm{CT}$ antigen to date. It elicits both cellular and humoral immune responses in a high proportion of patients with NY-ESO-1-expressing tumors [26]. These spontaneously occurring immune responses in cancer patients strongly support the concept of immunosurveillance. Several MHC class I- and class II-restricted epitopes from NY-ESO-1, which are recognized by CD8+ cytotoxic and CD4+ helper T cells, respectively $[27,28]$, have been characterized. These include epitopes restricted by MHC molecules that are relatively common in the Caucasian population such as the MHC class I molecules HLA-A2, HLA-A24 and HLA$\mathrm{B} 35$, as well as the MHC class II molecules HLA-DR4 and HLA-DP4. These achievements are particularly important because they facilitate the monitoring of vaccine-induced and spontaneous immune responses in cancer patients. 


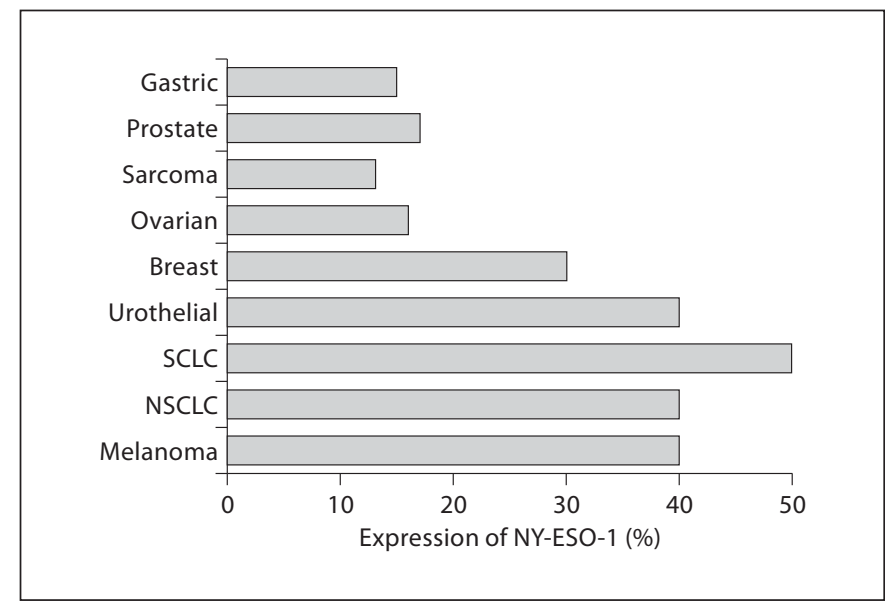

Fig. 1. NY-ESO-1 expression in various types of cancer. The percentages of different tumors positive for NY-ESO-1 were derived from at least 300 independent biopsies that were analyzed by immunohistochemistry. A tumor was considered positive when $>5 \%$ of the cells were stained.

The relevance of NY-ESO- 1 as a tumor antigen is illustrated by observations we made recently on a 61-year-old male patient who was diagnosed with metastatic melanoma with an unknown primary in March 2001 (ZH-311). The involved inguinal mass was widely excised and expressed NY-ESO-1. Upon immunization with recombinant fowlpox virus (rFV)/NY-ESO-1 in March 2004, his liver and lymph node metastases significantly decreased and no further lesions developed initially. However, in March 2005 he developed a single brain metastasis, which was resected, and NY-ESO-1 $1^{-}$. Because the primary tumor was never detected, the interpretation is that it was controlled and eventually eliminated by the spontaneous NY-ESO-1-specific immunity, an example of effective immune surveillance in vivo. The patient responded to $\mathrm{rFV} /$ NY-ESO-1 immunization with increased humoral and cellular immunity against NY-ESO-1, which was presumably responsible for the initial control and remission of disease. We assume that the subsequent NY-ESO-1- metastases developed as a result of immunological pressure and can be seen as an example of immunoediting.

\section{Immunotherapy as an Integrated Approach in Cancer Treatment}

After two decades of immunotherapy in preclinical models for cancer and patients, it is clear that significant hurdles, which prevent the induction of sustained tumor- specific effector functions in cancer patients, exist. The major aim for cancer immunotherapy is to identify these hurdles and to design treatments to circumvent these. The field of immunoregulation has made great progress during the last years, and many of the cells and factors involved in immunoregulation seem to impinge on tumor-specific immunity as well. First, tumor-specific T cells may be unable to infiltrate the tumor. Second, tumor antigens may be (ectopically) expressed in the thymus, which may purge the repertoire of tumor-specific T cells from high-avidity clones. Third, tumor-derived antigens are presumably presented to naïve $\mathrm{T}$ cells by steady-state dendritic cells, which may result in robust peripheral $\mathrm{T}$ cell tolerance. Fourth, chronic presentation of antigen may functionally or physically exhaust specific effector cells. Fifth, regulatory T cells in the tumor microenvironment block local $\mathrm{T}$ cell function or block the priming of tumor-specific T cells. Finally, the tumor environment may produce soluble factors, such as IL-10 and TGF- $\beta$, or promote the presence of myeloid-derived suppressor cells, all of which locally suppress $\mathrm{T}$ cell effector function.

The ultimate goal of cancer immunotherapy is to immunize patients with a tumor-associated antigen together with an adjuvant to stimulate innate immune defense. Because the immune system evolved to combat pathogens, immunization under conditions that mimic an infection is considered to be crucial for the induction of protective immunity. Compared to prophylactic vaccination, where an immune response is induced with a foreign antigen, therapeutic vaccination has proven to be more demanding. It is thought that prolonged antigen presentation under noninflammatory conditions, which may occur during persistent viral infections such as $\mathrm{HBV}$ or HIV or in cancer patients, results in subversion of the immune response by (partial) tolerization or exhaustion of specific T cells. Thus, besides an immunogenic antigen and an adjuvant, the vaccine presumably must contain a treatment modality that interferes with ongoing immunoregulation in order to be effective in cancer patients.

At present, clinical trials are under way that integrate the issues discussed above. For instance, treatment with antibodies that block CTLA- 4 or PD-1 have resulted in objective clinical responses in some patients. It may be worth designing trials that combine both antibodies, as there is evidence that both regulatory pathways are nonredundant. It is only recently that trials have started in which blockade of CTLA-4 or PD-1 is combined with active immunization or with active immunization plus preceding lymphodepletion. The latter approach may be promising, as lymphodepletion removes many regulatory 
cells from the patients before the new thymic emigrant $T$ cells are confronted with the vaccine.

In addition to vaccination with recombinant pathogens, recombinant proteins or (long) peptides in order to induce an integrated (antibodies and T cells) and tumorspecific immune response, the therapeutic potential of antibodies against tumor-associated, intracellular antigens is being investigated. To this end, we generated a fully human monoclonal IgG that recognizes NY-ESO-1. We cloned the B cell receptor (IgG) from EBV-transformed B cells of a cancer patient with high titers of spontaneous IgG against NY-ESO-1 and produced the human monoclonal IgG as a recombinant protein. The advantage of this approach is that we generate antibodies that are biologically relevant and probably safe, as they were derived directly from patients. We propose that high levels of NY-ESO-1-specific IgG will localize to otherwise damaged tumor tissues and form immune complexes with
NY-ESO-1 that is released from apoptotic or necrotic tumors. Those immune complexes will subsequently be taken up efficiently by dendritic cells for antigen presentation to NY-ESO-1-specific T cells. Cell death or necrosis of tumors, and thus presumably the therapeutic effect of antibodies, can be enhanced by radiotherapy, chemotherapy or other tumoricidal interventions. At present, patient-derived cancer-specific antibodies are highly promising agents for the initiation of an integrated tumor-specific immune response in cancer patients in the context of multimodal treatment approaches to combat cancer.

\section{Disclosure Statement}

The authors declare that no financial or other conflict of interest exists in relation to the content of the article.

\section{References}

1 Burnet M: Cancer; a biological approach. I. The processes of control. Br Med J 1957;1: 779-786.

2 Dunn GP, Bruce AT, Ikeda H, Old LJ, Schreiber RD: Cancer immunoediting: from immunosurveillance to tumor escape. Nat Immunol 2002;3:991-998.

3 Dunn GP, Old LJ, Schreiber RD: The three Es of cancer immunoediting. Annu Rev Immunol 2004;22:329-360.

4 Dunn GP, Koebel CM, Schreiber RD: Interferons, immunity and cancer immunoediting. Nat Rev Immunol 2006;6:836-848.

5 Shankaran V, Ikeda H, Bruce AT, White JM, Swanson PE, Old LJ, Schreiber RD: IFNgamma and lymphocytes prevent primary tumour development and shape tumour immunogenicity. Nature 2001;410:1107-1111.

6 Jäger D, Jäger E, Knuth A: Immune responses to tumour antigens: implications for antigen specific immunotherapy of cancer. J Clin Pathol 2001;54:669-674.

7 Clemente CG, Mihm MC Jr, Bufalino R, Zurrida S, Collini P, Cascinelli N: Prognostic value of tumor infiltrating lymphocytes in the vertical growth phase of primary cutaneous melanoma. Cancer 1996;77:1303-1310.

8 Hartveit F: Breast cancer: poor short-term prognosis in cases with moderate lymphocyte infiltration at the tumour edge: a preliminary report. Oncol Rep 1998;5:423-426.

9 Schumacher K, Haensch W, Roefzaad C, Schlag PM: Prognostic significance of activated CD8(+) $\mathrm{T}$ cell infiltrations within esophageal carcinomas. Cancer Res 2001;61: 3932-3936.
10 Funada Y, Noguchi T, Kikuchi R, Takeno S, Uchida Y, Gabbert HE: Prognostic significance of CD8+ T cell and macrophage peritumoral infiltration in colorectal cancer. Oncol Rep 2003;10:309-313.

11 Guidoboni M, Gafa R, Viel A, Doglioni C, Russo A, Santini A, Del Tin L, Macri E, Lanza G, Boiocchi M, Dolcetti R: Microsatellite instability and high content of activated cytotoxic lymphocytes identify colon cancer patients with a favorable prognosis. Am J Pathol 2001;159:297-304.

12 Naito Y, Saito K, Shiiba K, Ohuchi A, Saigenji K, Nagura H, Ohtani H: CD8+ T cells infiltrated within cancer cell nests as a prognostic factor in human colorectal cancer. Cancer Res 1998;58:3491-3494.

13 Zhang L, Conejo-Garcia JR, Katsaros D, Gimotty PA, Massobrio M, Regnani G, Makrigiannakis A, Gray H, Schlienger K, Liebman MN, Rubin SC, Coukos G: Intratumoral T cells, recurrence, and survival in epithelial ovarian cancer. N Engl J Med 2003;348:203213.

14 Curiel TJ, Coukos G, Zou L, Alvarez X, Cheng P, Mottram P, Evdemon-Hogan M, Conejo-Garcia JR, Zhang L, Burow M, Zhu Y, Wei S, Kryczek I, Daniel B, Gordon A, Myers L, Lackner A, Disis ML, Knutson KL, Chen L, Zou W: Specific recruitment of regulatory $\mathrm{T}$ cells in ovarian carcinoma fosters immune privilege and predicts reduced survival. Nat Med 2004;10:942-949.
15 MacKie RM, Reid R, Junor B: Fatal melanoma transferred in a donated kidney 16 years after melanoma surgery. N Engl J Med 2003; 348:567-568.

16 Waterhouse $\mathrm{P}$, Penninger JM, Timms E, Wakeham A, Shahinian A, Lee KP, Thompson CB, Griesser H, Mak TW: Lymphoproliferative disorders with early lethality in mice deficient in Ctla-4. Science 1995;270:985988.

17 Sato E, Olson SH, Ahn J, Bundy B, Nishikawa H, Qian F, Jungbluth AA, Frosina D, Gnjatic S, Ambrosone C, Kepner J, Odunsi T, Ritter G, Lele S, Chen YT, Ohtani H, Old LJ, Odunsi K: Intraepithelial CD8+ tumor-infiltrating lymphocytes and a high CD8+/regulatory $\mathrm{T}$ cell ratio are associated with favorable prognosis in ovarian cancer. Proc Natl Acad Sci USA 2005;102:18538-18543.

18 Kline J, Brown IE, Zha YY, Blank C, Strickler J, Wouters H, Zhang L, Gajewski TF: Homeostatic proliferation plus regulatory $\mathrm{T}$ cell depletion promotes potent rejection of B16 melanoma. Clin Cancer Res 2008;14: 3156-3167.

19 Knuth A, Danowski B, Oettgen HF, Old LJ: T-cell-mediated cytotoxicity against autologous malignant melanoma: analysis with interleukin 2-dependent T-cell cultures. Proc Natl Acad Sci USA 1984;81:3511-3515.

20 van der Bruggen P, Traversari C, Chomez P, Lurquin C, De Plaen E, Van den Eynde B, Knuth A, Boon T: A gene encoding an antigen recognized by cytolytic $\mathrm{T}$ lymphocytes on a human melanoma. Science 1991;254: 1643-1647. 
21 Chen YT, Scanlan MJ, Sahin U, Tureci O, Gure AO, Tsang S, Williamson B, Stockert E, Pfreundschuh M, Old LJ: A testicular antigen aberrantly expressed in human cancers detected by autologous antibody screening. Proc Natl Acad Sci USA 1997;94:1914-1918.

22 Stevenson BJ, Iseli C, Panji S, Zahn-Zabal M, Hide W, Old LJ, Simpson AJ, Jongeneel CV: Rapid evolution of cancer/testis genes on the X chromosome. BMC Genomics 2007;8:129.

23 Tinguely M, Jenni B, Knights A, Lopes B, Korol D, Rousson V, Curioni Fontecedro A, Cogliatti SB, Bittermann AG, Schmid U, Dommann-Scherrer C, Maurer R, Renner C, Probst-Hensch NM, Moch H, Knuth A, Zippelius A: MAGE-C1/CT-7 expression in plasma cell myeloma: sub-cellular localization impacts on clinical outcome. Cancer Sci 2008;99:720-725.
24 Lee SY, Obata Y, Yoshida M, Stockert E, Williamson B, Jungbluth AA, Chen YT, Old LJ, Scanlan MJ: Immunomic analysis of human sarcoma. Proc Natl Acad Sci USA 2003;100: 2651-2656.

25 Van den Eynde B, Peeters O, De Backer O, Gaugler B, Lucas S, Boon T: A new family of genes coding for an antigen recognized by autologous cytolytic T lymphocytes on a human melanoma. J Exp Med 1995;182:689698.

26 Jäger E, Chen YT, Drijfhout JW, Karbach J, Ringhoffer M, Jager D, Arand M, Wada H, Noguchi Y, Stockert E, Old LJ, Knuth A: Simultaneous humoral and cellular immune response against cancer-testis antigen NYESO-1: definition of human histocompatibility leukocyte antigen (HLA)-A2-binding peptide epitopes. J Exp Med 1998;187:265270.
27 Jäger E, Jäger D, Karbach J, Chen YT, Ritter G, Nagata Y, Gnjatic S, Stockert E, Arand M, Old LJ, Knuth A: Identification of NY-ESO-1 epitopes presented by human histocompatibility antigen (HLA)-DRB4*0101-0103 and recognized by CD4(+) T lymphocytes of patients with NY-ESO-1-expressing melanoma. J Exp Med 2000;191:625-630.

28 Jäger E, Karbach J, Gnjatic S, Jager D, Maeurer M, Atmaca A, Arand M, Skipper J, Stockert E, Chen YT, Old LJ, Knuth A: Identification of a naturally processed NY-ESO-1 peptide recognized by $\mathrm{CD} 8+\mathrm{T}$ cells in the context of HLA-B51. Cancer Immun 2002;2: 12. 